\title{
Monosomy 22
}

INSERM

\section{Source}

INSERM. (1999). Orphanet: an online rare disease and orphan drug data base.

Monosomy 22. ORPHA:96123

A rare autosomal anomaly syndrome, with a highly variable phenotype, typically characterized by short length, joint abnormalities (e.g. dysplasia, hyperextensibility, contractures, dislocation), congenital cardiac defects, and craniofacial dysmorphism (incl. microcephaly, a high, prominent, narrow and/or hairy forehead, epicanthus, upwardslanting and/or small palpebral fissures, broad, high or depressed nasal bridge and malformed ears). Delayed motor development and intellectual disability is observed in patients not presenting early demise. 